\title{
Association between serum alkaline phosphatase and C-reactive protein in the United States National Health and Nutrition Examination Survey 2005-2006
}

\author{
Matthew Webber, Aisling Krishnan, Neil G. Thomas \\ and Bernard M.Y. Cheung*
}

School of Clinical and Experimental Medicine, College of Medical and Dental Sciences, University of Birmingham, Birmingham, UK

\begin{abstract}
Background: Alkaline phosphatase (ALP) is a widely used marker for skeletal and hepatobiliary disorders, but its activity is also increased in atherosclerosis and peripheral vascular disease. It is an inflammatory marker like C-reactive protein (CRP). We therefore analyzed its relationship with CRP in the United States National Health and Nutrition Examination Survey (NHANES) 2005-2006.

Methods: The analysis included 4155 men and non-pregnant women over the age of 20 years. The relationship between log-transformed ALP and plasma CRP was analyzed using univariate and multivariate models.

Results: ALP activity was significantly correlated with age, waist circumference, body mass index, blood pressure, exercise, alcohol, triglycerides, and other liver enzymes after adjusting for age, gender and ethnicity $(p<0.001)$. ALP was significantly associated with a higher frequency of cardiovascular disease $(p=0.02)$, hypertension $(p=0.01)$ hypercholesterolemia $(p=0.04)$, and diabetes $(p=0.02)$. Compared to the lowest quartile of ALP, the adjusted odds ratio (OR) associated with the highest quartile were $1.9[95 \%$ confidence intervals (CI) 1.1-3.5], 1.6 (95\% CI 1.0-2.5), 1.5 (95\% CI 1.1-2.1) and 1.7 (95\% CI 1.0-2.4) for cardiovascular disease, hypertension, hypercholesterolemia, and diabetes, respectively. In multivariate analysis, log ALP was an independent predictor of $\log \mathrm{CRP}\left(\mathrm{p}=1.0 \times 10^{-6}\right)$. A multivariate model that included log ALP, ethnicity, glycohemoglobin, waist circumference, albumin, apolipoprotein B, $\gamma$-glutamyltransferase and uric acid explained $40 \%$ of the variance in $\log$ CRP.
\end{abstract}

Conclusions: ALP is a marker of cardiometabolic risk, but it needs to be tested as part of a multivariate model in prospective studies.

Clin Chem Lab Med 2010;48:167-73.

*Corresponding author: Prof. Bernard M.Y. Cheung, University Department of Medicine, Queen Mary Hospital, Hong Kong, China

Phone: +852 28554049, Fax: +852 28186474,

E-mail: mycheung@hkucc.hku.hk

Received August 3, 2009; accepted October 15, 2009;

previously published online December 4, 2009
Keywords: alkaline phosphatase; cardiovascular disease; C-reactive protein; NHANES.

\section{Introduction}

According to the World Health Organization, $\sim 17$ million people every year die from cardiovascular events, particularly myocardial infarction and stroke (1). Arterial inflammation has recently emerged as a central pathophysiological mechanism in the development and progression of atherosclerotic disease, and plays a major role in adverse cardiovascular outcomes (2-4). During the process of atherosclerosis, there is an accumulation of inflammatory cytokines and activation of the acute phase response, leading to the release of C-reactive protein (CRP) from the liver (5). CRP is widely used and an easily measured biomarker of systemic inflammation and is also known to be a powerful indicator of cardiovascular risk (6-9). In obesity, there is an increase in CRP concentrations. Numerous cross-sectional epidemiological studies have demonstrated a correlation between CRP concentrations and multiple variables related to cardiovascular disease and the metabolic syndrome (10-12). It is also known that increased CRP concentrations can predict adverse outcomes in patients with angina $(6,13)$ and peripheral vascular disease (12).

Alkaline phosphatase (ALP) belongs to a group of ubiquitous metalloenzymes that catalyze the hydrolysis of monophosphate esters at alkaline $\mathrm{pH}$, but its exact physiologic function is unknown. ALP is routinely used in the diagnosis and follow-up of osteoporosis and hepatobiliary disorders since it originates from bone and liver. ALP can also be found to a lesser extent in the intestines, kidneys and the placenta (14). Regan and Nagao, isoenzymes of ALP that are present in the placenta and in neoplastic lesions, respectively, are used in analysis during gestation and in non-physiologic conditions. ALP is also found in white blood cells including neutrophils, eosinophils, and basophils of many species, including humans, horses, and cattle. ALP is increased in the metabolic syndrome and correlates with plasma CRP concentrations $(2,15,16)$. In an epidemiological study in Hong Kong Chinese, ALP was related to a number of other identifiable risk factors (16). In men, plasma ALP was significantly higher in patients with diabetes and in those who smoked. In women, plasma ALP was significantly related to age, body mass index (BMI), systolic blood pressure (BP), diabetes, triglyceride concentrations and 
menopausal status (16). High serum activities of ALP have also been noted in patients with peripheral arterial disease (PAD) (17). PAD is a systemic vascular disease, associated with widespread arterial atherosclerosis and vascular inflammation.

Its correlation with CRP, inflammation, obesity, and atherosclerosis makes ALP a potential diagnostic marker or predictor of cardiovascular disease. At present, there are only a limited number of small scale studies on this aspect of ALP. Therefore, we analyzed the relationship between ALP and CRP in a large representative population.

\section{Materials and methods}

\section{Study population}

For our analysis, data were extracted from the open database of the United States National Health and Nutrition Examination Survey 2005-2006 (NHANES 2005-2006). This is part of a continuous group of studies designed to provide health and nutritional information for adults and children in the USA (18). All participants gave informed consent prior to examination, and the survey was approved by the National Center for Health Statistics, specifically the Center for Disease Control and Prevention Institutional Review Board Program. Participants were examined in well equipped mobile examination centers located around the USA. Examinations were standardized according to the environment, equipment used and specimen collection. Participants were selected using a complex stratified sample design, which included members of the civilian, non-institutionalized USA population. All individuals were assigned a numerical weight to account for variations in response and unequal selection probabilities. The selection process included oversampling of subgroups of special interest, such as African Americans, Mexican Americans, adolescents, low-income individuals, and people aged $\geq 60$ years. Among the 10,348 participants eligible for inclusion, 9860 had their serum ALP, alanine aminotransferase (ALT), aspartate aminotransferase (AST), $\gamma$-glutamyltransferase (GGT) and CRP measured. We then excluded 5369 participants under the age of 20 years, 57 of whom were pregnant, and 336 pregnant women who were aged 20 years or older. Therefore, 4155 participants were included in our analysis.

\section{Variables of interest}

Demographic variables including age, race/ethnicity, and pregnancy status were based on a 'Sample Person and Family Demographics' questionnaire, completed by participants prior to physical examination. Pregnancy status was determined by testing urine. The population was classified into ethnic subgroups including Mexican American, other Hispanic, non-Hispanic whites, non-Hispanic blacks, and others. Smoking, alcohol intake, physical activity, and cardiovascular disease status were also based on self-reported questionnaires. For the purpose of our analysis, alcohol intake was defined as consuming at least one alcoholic drink a week during the past year. Smokers were defined as participants who smoked 100 or more cigarettes in their lifetime. Physical activity was defined as taking part in moderate to vigorous levels of activity at least once a month.

Waist circumference, weight and BP were obtained by trained personnel in the Mobile Examination Centers. Weight was taken using a Toledo digital scale, recorded in pounds and later converted to kilograms. BMI was calculated as the weight $(\mathrm{kg})$ divided by the square of the height (m). BP was measured by a certified NHANES physician using a calibrated mercury manometer and a Littmann cardiology stethoscope.

History of cardiovascular disease, namely, coronary heart disease, congestive heart failure, angina, stroke and myocardial infarction, was obtained from self-reported questionnaires. Diabetes was defined as being diagnosed with diabetes by a physician at some point in one's lifetime, currently taking insulin, having a resting plasma glucose concentration $>200 \mathrm{mg} / \mathrm{dL}(11.1 \mathrm{mmol} / \mathrm{L})$, or a fasting glucose of $>126 \mathrm{mg} / \mathrm{dL}(7.0 \mathrm{mmol} / \mathrm{L})$. Hypercholesterolemia was defined as diagnosis by a doctor, currently taking cholesterol lowering medication, or having a total serum cholesterol $\geq 240 \mathrm{mg} / \mathrm{gL}$ ( $6.2 \mathrm{mmol} / \mathrm{L}$ ). Hypertension was defined as diagnosis by a doctor, currently taking BP lowering medication or having a resting $\mathrm{BP} \geq 140 / 90 \mathrm{~mm} \mathrm{Hg}$.

\section{Laboratory measurements}

Plasma CRP was measured in participants using a latex enhanced nephelometric method. Glycohemoglobin was measured using an assay for SA1c and La1c (two forms of glycated hemoglobin) which were individually resolved using a chromatogram and analyzed using a Tosoh Alc 2.2 Plus Glycohaemoglobin Analyzer (Tosoh Meics, Inc, San Francisco, CA, USA). High-density lipoprotein (HDL) and low-density lipoprotein (LDL) cholesterol were measured in the blood using either a Hitachi 717 or Hitachi 912 analyzer (Roche, formerly Boehringer-Mannheim Diagnostics, Indianapolis, IN, USA). Albumin concentrations were measured using a bichromatic digital endpoint method. Serum ALP, ALT, AST, and GGT activities were determined with a Beckman Synchron LX20 analyzer (Beckman Coulter Inc., Fullerton, CA, USA). The adult reference range for ALP in NHANES is 36-113 U/L. Triglycerides were measured using a Hitachi 717 analyzer, glucose by use of a rate method utilizing a Beckman oxygen electrode and apolipoprotein B by means of a Dade Behring BN100 Nephelometer (Dade Behring Diagnostics Inc., Somerville, NJ, USA). Samples for ALP and CRP analysis that were not assayed within $48 \mathrm{~h}$ were frozen and thawed only once to avoid analyte degradation and abnormal over expression. A more detailed explanation of the study design, interview techniques, measurement procedures, and protocol is given on the NHANES website (18).

\section{Statistical analysis}

Data from the 4155 participants were analyzed using the complex sampling function of SPSS version 17.0 for Apple Macintosh (SPSS Inc, Chicago, IL, USA), to take into account the oversampling used in the NHANES 2005-2006 study. MEC examination weights were used in all analyses to adjust for oversampling and non-response bias. Variables that had a skewed distribution were log transformed in all correlation and regression analysis. Partial bivariate correlation was performed to analyze the relationship between CRP, ALP and other variables while adjusting for age, gender and ethnicity. pValues were obtained using linear regression or logistic regression analysis where appropriate, using the complex samples function. Multiple linear regression was used to identify independent variables, including log ALP, that were related to log CRP. Variables that showed significant correlation with CRP in bivariate analysis were entered stepwise. A variable was retained if it was independently associated with $\log$ CRP $(p<0.05)$. Serum ALP was categorized into quartiles according to the weighted distribution in the sample. The association of serum ALP activity with cardiovascular 
disease, hypertension and diabetes was then assessed using ALP quartiles as a categorical variable in multiple logistic regression.

\section{Results}

Table 1 shows the characteristics of all study participants according to gender. Compared to women, men had a greater waist circumference, weight, systolic and diastolic BP, and higher ALP, plasma LDL and triglycerides, but lower total cholesterol and CRP concentrations. Also, men were more likely to drink alcohol, smoke cigarettes and suffer from cardiovascular disease.

Table 2 shows the partial bivariate correlation between log-transformed ALP and CRP with other variables after adjusting for gender, age and ethnicity (Mexican American, other Hispanic, non-Hispanic white, non-Hispanic black, and other). In men, log ALP was significantly correlated with age, waist circumference, BMI, BP, smoking, alcohol intake, HDL, albumin, glycohemoglobin, ALT, AST and GGT. Log CRP was correlated to all the aforementioned variables as well as with weight, exercise, plasma triglycerides, glucose and uric acid. In women, $\log$ ALP and log CRP were significantly correlated with age, waist circumference, weight, BMI, BP, exercise, smoking, alcohol intake, total cholesterol, LDL, HDL, apolipoprotein B, triglycerides, albumin, glucose, uric acid, ALT and GGT. Log ALP was significantly correlated with CRP after controlling for gender, age, and ethnicity $(\mathrm{r}=0.28, \mathrm{p}<0.001)$.

Table 3 shows the results of stepwise multiple linear regression analysis. The model was adjusted for gender, age, ethnicity, hypertension, hypercholesterolemia, triglycerides,

Table 1 Characteristics of the study participants.

\begin{tabular}{|c|c|c|c|}
\hline & Male $(\mathrm{n}=2147)$ & Female $(n=2008)$ & Combined $(n=4115)$ \\
\hline Age, years & $46.1 \pm 0.8$ & $48.2 \pm 0.7$ & $47.2 \pm 0.7$ \\
\hline \multicolumn{4}{|l|}{ Race/ethnicity } \\
\hline Mexican American & $8.8 \pm 1.2$ & $6.8 \pm 0.8$ & $7.8 \pm 1.0$ \\
\hline Other Hispanic & $3.2 \pm 0.9$ & $3.4 \pm 0.7$ & $3.3 \pm 0.8$ \\
\hline Non-Hispanic white & $73.2 \pm 2.7$ & $72.5 \pm 2.8$ & $72.8 \pm 2.7$ \\
\hline Non-Hispanic black & $10.4 \pm 1.7$ & $11.6 \pm 2.1$ & $11.0 \pm 1.9$ \\
\hline Others & $4.5 \pm 0.6$ & $5.7 \pm 0.8$ & $5.1 \pm 0.6$ \\
\hline Waste circumference, $\mathrm{cm}$ & $101.4 \pm 0.7$ & $94.1 \pm 0.8$ & $97.7 \pm 0.7$ \\
\hline Weight, kg & $89.0 \pm 0.8$ & $75.1 \pm 0.9$ & $81.9 \pm 0.7$ \\
\hline BMI, $\mathrm{kg} / \mathrm{m}^{2}$ & $28.6 \pm 0.3$ & $28.6 \pm 0.3$ & $28.6 \pm 0.3$ \\
\hline \multicolumn{4}{|l|}{ Blood pressure } \\
\hline Systolic BP, mm Hg & $123.0 \pm 0.5$ & $120.7 \pm 0.8$ & $121.9 \pm 0.6$ \\
\hline Diastolic BP, mm Hg & $71.5 \pm 0.5$ & $69.1 \pm 0.5$ & $70.3 \pm 0.4$ \\
\hline Exercise, $\%$ & $68.1 \pm 2.1$ & $66.2 \pm 1.4$ & $67.1 \pm 1.5$ \\
\hline \multicolumn{4}{|l|}{ Smokers, $\%$} \\
\hline Never & $43.5 \pm 1.8$ & $57.4 \pm 1.5$ & $50.6 \pm 1.4$ \\
\hline Former & $28.8 \pm 1.3$ & $21.5 \pm 1.0$ & $25.1 \pm 1.0$ \\
\hline Current & $27.7 \pm 1.6$ & $21.1 \pm 1.3$ & $24.3 \pm 1.2$ \\
\hline Alcohol drinking, $\%$ & $40.1 \pm 1.6$ & $21.7 \pm 1.6$ & $30.7 \pm 1.5$ \\
\hline Cardiovascular disease, $\%$ & $9.4 \pm 0.8$ & $8.3 \pm 0.9$ & $8.8 \pm 0.6$ \\
\hline Hypertension, \% & $35.1 \pm 1.2$ & $35.5 \pm 1.5$ & $35.3 \pm 1.1$ \\
\hline Diabetes, $\%$ & $11.1 \pm 0.9$ & $11.0 \pm 0.9$ & $11.0 \pm 0.7$ \\
\hline Hypercholesterolemia, \% & $38.5 \pm 1.6$ & $38.1 \pm 1.7$ & $38.3 \pm 1.4$ \\
\hline Total cholesterol, mmol/L & $5.1 \pm 0.03$ & $5.3 \pm 0.02$ & $5.2 \pm 0.02$ \\
\hline $\mathrm{LDL}, \mathrm{mmol} / \mathrm{L}$ & $3.01 \pm 0.04$ & $2.97 \pm 0.04$ & $2.99 \pm 0.03$ \\
\hline $\mathrm{HDL}, \mathrm{mmol} / \mathrm{L}$ & $1.3 \pm 0.008$ & $1.5 \pm 0.02$ & $1.4 \pm 0.0005$ \\
\hline Apolipoprotein B, g/L & $1.04 \pm 0.01$ & $0.99 \pm 0.02$ & $1.01 \pm 0.01$ \\
\hline Triglycerides, $\mathrm{mmol} / \mathrm{L}^{\mathrm{a}}$ & $1.56(1.51-1.63)$ & $1.42(1.38-1.46)$ & $1.42(1.39-1.46)$ \\
\hline Albumin, g/L & $43.0 \pm 0.1$ & $42.0 \pm 0.2$ & $42.0 \pm 0.1$ \\
\hline Glucose, $\mathrm{mmol} / \mathrm{L}^{\mathrm{a}}$ & $5.4(5.3-5.42)$ & $5.3(5.2-5.4)$ & $5.4(5.3-5.5)$ \\
\hline Glycohemoglobin, $\%^{\mathrm{a}}$ & $5.3(5.4-5.5)$ & $5.4(5.4-5.5)$ & $5.4(5.4-5.5)$ \\
\hline Uric acid, $\mathrm{nM}^{\mathrm{a}}$ & $350.9(350.9-356.9)$ & $279.6(273.6-279.6)$ & $321.2(303.3-321.2)$ \\
\hline $\mathrm{ALP}, \mathrm{U} / \mathrm{L}^{\mathrm{a}}$ & $66.7(65.5-68.1)$ & $64.6(62.9-67.1)$ & $66.1(64.6-67.6)$ \\
\hline $\mathrm{ALT}, \mathrm{U} / \mathrm{L}^{\mathrm{a}}$ & $26.8(26.2-27.5)$ & $23.0(22.5-23.5)$ & $22.9(22.4-23.4)$ \\
\hline $\mathrm{AST}, \mathrm{U} / \mathrm{L}^{\mathrm{a}}$ & $26.0(25.5-26.6)$ & $24.2(23.8-24.6)$ & $24.6(24.0-24.5)$ \\
\hline GGT, U/L & $26.1(25.0-27.3)$ & $21.5(20.8-22.3)$ & $21.4(20.9-22.4)$ \\
\hline $\mathrm{CRP}, \mathrm{mg} / \mathrm{L}^{\mathrm{a}}$ & $1.6(1.5-1.8)$ & $2.1(1.9-2.4)$ & $1.8(1.7-2.0)$ \\
\hline
\end{tabular}

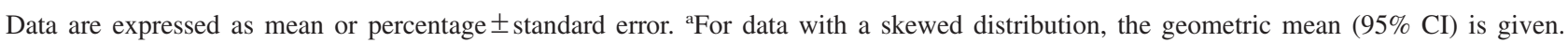
BMI, body mass index; BP, blood pressure; LDL, low-density lipoprotein; HDL, high-density lipoprotein; ALP, alkaline phosphatase; ALT, alanine aminotransferase; AST, aspartate aminotransferase; GGT, $\gamma$-glutamyltransferase; CRP, C-reactive protein. 
Table 2 Correlation between ALP and CRP with other variables of interest.

\begin{tabular}{|c|c|c|c|c|c|c|}
\hline & \multicolumn{3}{|c|}{ ALP, $\log \mathrm{U} / \mathrm{L}$} & \multicolumn{3}{|c|}{$\mathrm{CRP}, \log \mathrm{mg} / \mathrm{L}$} \\
\hline & Male & Female & Combined & Male & Female & Combined \\
\hline Age, years & 0.08 & 0.24 & 0.17 & 0.23 & 0.51 & 0.16 \\
\hline Waist circumference, $\mathrm{cm}$ & $0.08^{\mathrm{a}}$ & 0.24 & 0.15 & 0.41 & 0.51 & 0.47 \\
\hline Weight, kg & - & 0.21 & 0.08 & 0.36 & 0.47 & 0.42 \\
\hline BMI, $\mathrm{kg} / \mathrm{m}^{2}$ & $0.07^{\mathrm{a}}$ & 0.24 & 0.13 & 0.39 & 0.50 & 0.45 \\
\hline Systolic BP, mm Hg & $0.08^{\mathrm{b}}$ & 0.16 & 0.12 & 0.13 & 0.13 & 0.12 \\
\hline Diastolic BP, mm Hg & $0.08^{\mathrm{a}}$ & 0.15 & 0.10 & 0.12 & $0.07^{\mathrm{b}}$ & 0.10 \\
\hline Exercise, \% & - & -0.11 & -0.07 & -0.11 & -0.13 & -0.12 \\
\hline Smokers, $\%$ & $0.04^{\mathrm{b}}$ & $0.07^{\mathrm{b}}$ & $0.03^{\mathrm{a}}$ & $0.05^{\mathrm{a}}$ & $0.06^{\mathrm{a}}$ & 0.06 \\
\hline Alcohol drinking, $\%$ & $-0.12^{\mathrm{b}}$ & -0.14 & -0.14 & $-0.07^{\mathrm{a}}$ & -0.13 & -0.10 \\
\hline Total cholesterol, mmol/L & - & 0.10 & 0.06 & - & 0.11 & 0.07 \\
\hline $\mathrm{LDL}, \mathrm{mmol} / \mathrm{L}$ & - & $0.08^{\mathrm{b}}$ & - & - & -0.10 & - \\
\hline $\mathrm{HDL}, \mathrm{mmol} / \mathrm{L}$ & $-0.06^{\mathrm{b}}$ & $-0.15^{\mathrm{a}}$ & -0.09 & -0.22 & -0.25 & -0.24 \\
\hline Apolipoprotein B, g/L & - & 0.11 & $0.07^{\mathrm{a}}$ & - & 0.24 & 0.15 \\
\hline Triglycerides, $\mathrm{mmol} / \mathrm{L}^{\mathrm{c}}$ & - & 0.17 & 0.13 & 0.14 & 0.30 & 0.21 \\
\hline Albumin, g/L & -0.17 & $-0.13^{\mathrm{a}}$ & -0.15 & -0.34 & -0.40 & -0.37 \\
\hline Glucose, $\mathrm{mmol} / \mathrm{L}^{\mathrm{c}}$ & - & 0.14 & 0.12 & 0.13 & 0.20 & 0.17 \\
\hline Glycohemoglobin, $\%^{\mathrm{c}}$ & $0.09^{\mathrm{a}}$ & 0.19 & 0.14 & 0.19 & 0.24 & 0.22 \\
\hline Uric acid, $\mathrm{nM}^{\mathrm{c}}$ & - & 0.10 & 0.03 & 0.20 & 0.25 & 0.22 \\
\hline $\mathrm{ALP}, \mathrm{U} / \mathrm{L}^{\mathrm{c}}$ & - & - & - & 0.24 & 0.33 & 0.28 \\
\hline $\mathrm{ALT}, \mathrm{U} / \mathrm{L}^{\mathrm{c}}$ & $0.09^{\mathrm{a}}$ & 0.23 & 0.17 & $0.12^{\mathrm{b}}$ & 0.11 & 0.10 \\
\hline $\mathrm{AST}, \mathrm{U} / \mathrm{L}^{\mathrm{c}}$ & $0.12^{\mathrm{a}}$ & 0.17 & 0.22 & - & - & - \\
\hline GGT, U/L ${ }^{c}$ & 0.29 & 0.37 & 0.35 & 0.27 & 0.35 & 0.30 \\
\hline $\mathrm{CRP}, \mathrm{mg} / \mathrm{L}^{\mathrm{c}}$ & 0.24 & 0.33 & 0.28 & - & - & - \\
\hline
\end{tabular}

Partial correlation coefficients were calculated using sample weights and adjusted for age (except in age specific estimates), gender (except of gender specific estimates) and ethnicity (Mexican American, other Hispanic, non-Hispanic white, non-Hispanic black, and other). ${ }^{\mathrm{a}} \mathrm{p}<0.01$; ${ }_{\mathrm{b}}^{\mathrm{b}}<0.05 . \mathrm{p}<0.001$ for all other correlation coefficients. 'Data were log transformed in assessing $\mathrm{p}$ due to their skewed distribution. Nonsignificant values were omitted. BMI, body mass index; BP, blood pressure; LDL, low-density lipoprotein; HDL, high-density lipoprotein; ALP, alkaline phosphatase; ALT, alanine aminotransferase; AST, aspartate aminotransferase; GGT, $\gamma$-glutamyltransferase; CRP, C-reactive protein.

glycohemoglobin, and ALT. Independent predictor variables of CRP included ALP, glycohemoglobin, waist circumference, albumin, apolipoprotein B, GGT, and uric acid. In men, ALP, waist circumference, albumin, GGT, and uric acid were predictors. In women, ALP, glycohemoglobin, waist circumference, albumin, apolipoprotein B and GGT were predictors. ALP was a highly significant predictor of plasma CRP $\left(\mathrm{p}=1.0 \times 10^{-6}\right)$. The full model explained $40 \%$ of the variance in $\log$ CRP. ALP remained a significant independent predictor of CRP $\left(\mathrm{p}=2.0 \times 10^{-6}\right)$ after excluding 152 participants who had a self-reported history of liver disease.

Table 4 shows the frequencies (\%) of cardiovascular disease, hypertension, hypercholesterolemia and diabetes according to ALP quartiles. ALP was significantly associated

Table 3 Multivariate linear regression analysis of independent predictors of log CRP, mg/L.

\begin{tabular}{|c|c|c|c|c|c|c|}
\hline & \multicolumn{2}{|c|}{ Male $(n=2147)$} & \multicolumn{2}{|c|}{ Female $(n=2008)$} & \multicolumn{2}{|c|}{ Combined $(n=4155)$} \\
\hline & $\begin{array}{l}\text { Regression } \\
\text { coefficient }\end{array}$ & p-Value & $\begin{array}{l}\text { Regression } \\
\text { coefficient }\end{array}$ & p-Value & $\begin{array}{l}\text { Regression } \\
\text { coefficient }\end{array}$ & p-Value \\
\hline $\mathrm{ALP}, \mathrm{U} / \mathrm{L}^{\mathrm{a}}$ & 0.56 & $1.51 \times 10^{-4}$ & 0.57 & $1.60 \times 10^{-4}$ & 0.57 & $1.01 \times 10^{-6}$ \\
\hline Glycohemoglobin, $\%^{\mathrm{a}}$ & - & - & 0.03 & 0.07 & 0.34 & $4.45 \times 10^{-4}$ \\
\hline Waist circumference, $\mathrm{cm}$ & 0.009 & $1.79 \times 10^{-7}$ & 0.01 & $3.46 \times 10^{-7}$ & 0.01 & $1.06 \times 10^{-9}$ \\
\hline Albumin, g/L & -0.043 & $1.68 \times 10^{-5}$ & -0.049 & $7.15 \times 10^{-7}$ & -0.047 & $3.39 \times 10^{-8}$ \\
\hline Apolipoprotein $\mathrm{B}, \mathrm{g} / \mathrm{L}$ & - & - & 0.3 & 0.001 & 0.2 & 0.003 \\
\hline GGT, U/L & 0.23 & 0.003 & 0.31 & 0.002 & 0.26 & 0.001 \\
\hline Uric acid, $\mathrm{nmol} / \mathrm{L}^{\mathrm{a}}$ & $1.68 \times 10^{-5}$ & $3.60 \times 10^{-4}$ & $1.68 \times 10^{-5}$ & 0.25 & $1.68 \times 10^{-5}$ & $2.45 \times 10^{-4}$ \\
\hline $\mathrm{R}^{2}$ & 0.36 & - & 0.43 & - & 0.40 & - \\
\hline
\end{tabular}

${ }^{a}$ Data were log transformed in assessing $\mathrm{p}$ for trend due to their skewed distribution. The model was adjusted for gender, age, ethnicity (Mexican American, other Hispanic, non-Hispanic white, non-Hispanic black, others), smoking, hypertension, hypercholesterolemia, ALT ${ }^{\mathrm{a}}$, and triglycerides ${ }^{\mathrm{a}}$. ALP, alkaline phosphatase; GGT, $\gamma$-glutamyltransferase; ALT, alanine aminotransferase. 
Table 4 History of cardiovascular disease, hypertension, diabetes, and hypercholesterolemia according to quartiles of serum ALP, U/L.

\begin{tabular}{llllll}
\hline Characteristics & $\begin{array}{l}\text { Quartile 1 } \\
(<56)\end{array}$ & $\begin{array}{l}\text { Quartile 2 } \\
(56-68)\end{array}$ & $\begin{array}{l}\text { Quartile 3 } \\
(68-83)\end{array}$ & $\begin{array}{l}\text { Quartile 4 } \\
(\geq 84)\end{array}$ & p for trend \\
\hline $\mathrm{n}$ & 1115 & 1033 & 998 & 1009 & \\
Cardiovascular disease, \% & $5.6 \pm 0.7$ & $7.6 \pm 1.0$ & $9.6 \pm 1.1$ & $14.4 \pm 2.3$ & 0.02 \\
Hypertension, \% & $20.1 \pm 1.5$ & $23.5 \pm 0.9$ & $27.9 \pm 1.3$ & $36.5 \pm 3.0$ & 0.01 \\
Diabetes, \% & $7.5 \pm 1.0$ & $8.9 \pm 1.0$ & $13.3 \pm 0.9$ & $16.7 \pm 1.1$ & 0.02 \\
Hypercholesterolemia, \% & $30.5 \pm 2.1$ & $39.4 \pm 2.0$ & $40.7 \pm 1.7$ & $46.0 \pm 2.5$ & 0.04 \\
\hline
\end{tabular}

Data are expressed as mean percentage \pm standard error. ALP was log transformed due to its skewed distribution. p-Values were derived from multiple logistic regression after adjusting for age, gender and ethnicity (Mexican American, non-Hispanic white, non-Hispanic black, other Hispanic and others). ALP reference range: (36-113 U/L).

with cardiovascular disease $(\mathrm{p}=0.02)$, hypertension $(\mathrm{p}=$ 0.01) hypercholesterolemia $(\mathrm{p}=0.04)$, and diabetes $(p=0.02)$ after adjusting for age, gender, ethnicity and BMI in a multiple logistic regression model. Compared to the lowest quartile of ALP, the highest quartile of ALP had a higher odds of cardiovascular disease [odds ratio $(\mathrm{OR})=1.9,95 \%$ confidence intervals $(\mathrm{CI}) 1.1-3.5]$, hypertension $(\mathrm{OR}=1.58$, 95\% CI 1.0-2.5), hypercholesterolemia $(\mathrm{OR}=1.5,95 \% \mathrm{CI}$ 1.1-2.1) and diabetes $(\mathrm{OR}=1.6,95 \% \mathrm{CI} 1.0-2.4)$.

We repeated the analysis using NHANES 2004-2005 data and obtained similar results; serum ALP was also significantly related to CRP (data not shown).

\section{Discussion}

This is the first study of its size to report a significant association between the blood levels of ALP and CRP. Our study is consistent with previous reports showing increased ALP activity relating to metabolic syndrome risk factors and cardiovascular disease $(16,19)$.

In a previous study on Chinese individuals, the association between ALP and CRP was only significant in women (16). In NHANES, the association was similar in men and women. Whether the discrepancy was due to sample size or ethnicity requires further investigation. The relationship between CRP and ALP is consistent with epidemiological studies reporting the association between liver markers and the metabolic syndrome $(2,15)$. It has been reported in numerous cross-sectional studies that CRP is a predictor of cardiovascular disease (8-10, 20, 21). Like CRP, ALP is increased in nonalcoholic fatty liver disease and in the metabolic syndrome $(2,15)$, which are known to be risk factors for atherosclerosis and cardiovascular disease (22).

Apart from CRP, we found that ALP was also correlated with other cardiovascular risk factors, such as waist circumference, BP and lipid concentrations, and associated with an increased frequency of diabetes, hypercholesterolemia, hypertension and cardiovascular disease. These findings are consistent with reports that high ALP is associated with various cardiovascular diseases, such as PAD (17), left ventricular hypertrophy (23), secondary cardiac failure and diastolic dysfunction (24).
There may be a theoretical basis for the association between ALP and cardiovascular disease. Serum ALP is known to be higher in obese patients and may play a role in the mechanisms of adipogenesis $(14,16,25)$. ALP appears to be involved in lipid absorption and intestinal ALP activities may increase after a high fat meal $(26,27)$. Thus, increased ALP may be a marker of an atherogenic diet. ALP is also known to be negatively correlated with adiponectin (2), a hormone secreted by adipose tissues that predicts the development of type 2 diabetes (28) and hypertension (29) in prospective studies. In a secondary atherosclerotic plaque, there is vascular calcification (30), which is thought to be regulated by ALP (31). Emerging evidence from a prospective epidemiological study has suggested that vitamin D deficiency is correlated with higher rates of cardiovascular disease, especially in hypertensive patients (32). It is therefore tempting to speculate that vitamin D deficiency, a surrogate for cardiovascular disease, leads to hyperparathyroidism, high bone turnover, and increased ALP activities. This is a premise that warrants further study.

The JUPITER (Justification for the Use of Statins in Primary Prevention: An Intervention Trial Evaluating Rosuvastatin) trial showed that people with modest cardiovascular risk, but with increased CRP, benefited from statin therapy irrespective of their LDL concentrations (33). It would be of interest to determine from large randomized trials of statins if people with increased ALP activity and cardiovascular risk factors might also benefit from statins.

There are some limitations to our study. The relationship between ALP and CRP is an association and it is not possible to conclude that it is causal. Since the data are cross-sectional, we do not know if any changes in CRP immediately affect ALP activity. ALP is known to be raised in a number of diseases and the presence of unknown subclinical disease in participants may have confounded the relationship between ALP and CRP. The ALP measured in NHANES was in the serum and the origin of the enzyme is therefore unclear as ALP is present in many tissues in the body. Expression of ALP in the heart, vascular tissue, granulocytes or the liver may be altered in cardiovascular disease, but this needs to be investigated in further studies.

We cannot determine the potential benefits of an ALP test for cardiovascular disease at this time. The discriminating ability of an ALP test must be measured as part of prospec- 
tive studies, with respect to sensitivity and specificity in order to determine the utility of such a diagnostic tool. Similarly, the association between serum ALP and cardiovascular disease, with respect to the nature and direction of causation cannot be concluded from the results. Such conclusions should be drawn from randomized controlled trials of novel ALP inhibitors.

In conclusion, plasma ALP activity correlated significantly with plasma CRP concentrations, after controlling for confounding variables in a large, nationally representative sample population. CRP is known to be a good marker of cardiovascular risk (8), but measuring it requires a specific and costly test. ALP is a routinely measured liver function test, and thus does not represent an extra cost. This may make it an invaluable marker, not only in contemporary and future research studies, but also in historical and retrospective studies, and studies performed in developing countries. Although our results raise the possibility that it could be used as a marker of cardiovascular risk, further research is needed to assess the utility of ALP in a panel of markers of cardiovascular risk in large cohorts and in diverse ethnic populations.

\section{Acknowledgements}

We thank K.L. Ong for his advice on the study.

\section{Conflict of interest statement}

Authors' conflict of interest disclosure: The authors stated that there are no conflicts of interest regarding the publication of this article.

Research funding: None declared.

Employment or leadership: None declared.

Honorarium: None declared.

\section{References}

1. World Health Organization. Prevention of cardiovascular disease: guidelines for assessment and management of total cardiovascular risk. http://www.who.int/cardiovascular_diseases/guidelines/ Prevention_of_Cardiovascular_Disease/en/index.html. Accessed March 2008.

2. Kerner A, Avizohar O, Sella R, Bartha P, Zinder O, Markiewicz $\mathrm{W}$, et al. Association between elevated liver enzymes and Creactive protein. Possible hepatic contribution to systemic inflammation in the metabolic syndrome. Arterioscler Thromb Vasc Biol 2005;25:193-7.

3. Libby P, Ridker M, Maseri AM. Inflammation and atherosclerosis. Circulation 2002;105:1135-43.

4. Russel R. Atherosclerosis - an inflammatory disease. N Engl J Med 1999;340:115-26.

5. Sumner AD, Eid S, Parks A, Edris B, Reed III JF. Increasing prevalence of peripheral artery disease in the United States: results from the national health and nutrition examination survey (1999-2004). Circulation [abstract] 2007;116:II-780.

6. Wildman RP, Muntner P, Chen J, Sutton-Tyrrell K, He J. Relation of inflammation to peripheral arterial disease in the national health and nutrition examination survey, 1999-2002. Am J Cardiol 2005;96:1579-83.

7. Vu JD, Vu JB, Pio JR, Malik S, Franklin SS, Chen RS, et al. Impact of C-reactive protein on the likelihood of peripheral arterial disease in United States adults with the metabolic syndrome, diabetes mellitus, and preexisting cardiovascular disease. Am J Cardiol 2005;96:655-8.

8. Ridker PM, Rifai N, Rose L, Buring JE, Cook NR. Comparison of C-reactive protein and low-density lipoprotein cholesterol levels in the prediction of first cardiovascular events. N Engl J Med 2002;347:1557-65.

9. Yudkin JS, Stehouwer CD, Emeis JJ, Coppack SW. C-Reactive protein in healthy subjects: associations with obesity, insulin resistance, and endothelial dysfunction: a potential role for cytokines originating from adipose tissue? Arterioscler Thromb Vasc Biol 1999;19:972-8.

10. Danesh J, Collins R, Appleby P. Association of fibrinogen, Creactive protein or leukocyte count with coronary heart disease: meta analysis of prospective studies. J Am Med Assoc 1998; 279:1477-82.

11. Festa A, D'Agostino R, Howard G, Mykkänen L, Tracy RP, Haffner SM. Chronic subclinical inflammation as part of the insulin resistance syndrome: the insulin resistance atherosclerosis study (IRAS). Circulation 2000;102:42-7.

12. Lane JS, Vittinghoff E, Lane KT, Hiramoto JS, Messina LM. Risk factors for premature peripheral vascular disease: results for the national health and nutritional survey, 1999-2002. J Vasc Surg 2006;44:319-24.

13. Liuzzo G, Biasucci LM, Gallimore JR, Grillo RL, Rebuzzi AG, Pepys MB, et al. The prognostic value of C-reactive protein and serum amyloid a protein in severe unstable angina. N Engl J Med 1994;333:417-24.

14. Ali AT, Penny CB, Paiker JE, van Niekerk C, Smit A, Ferris $\mathrm{WF}$, et al. Alkaline phosphatase is involved in the control of adipogenesis in the murine preadipocyte cell line, 3T3-L1. Clin Chim Acta 2005;354:101-9.

15. Hanley AJ, Williams K, Fests A, Wagenknecht LE, D'Agostino RB, Haffner SM. Liver markers and the development of the metabolic syndrome. The insulin resistance atherosclerosis study. Diabetes 2005;54:3140-7.

16. Cheung BM, Ong KL, Cheung RV, Wong LY, Wat NM, Tam $\mathrm{S}$, et al. Association between plasma alkaline phosphatase and C-reactive protein in Hong Kong Chinese. Clin Chem Lab Med 2008;46:523-7.

17. Cheung BM, Ong KL, Wong LY. Elevated serum alkaline phosphatase and peripheral arterial disease in the United States National Health and Nutrition Examination Survey 1999-2004. Int J Cardiol 2009;135:156-61.

18. Centers for Disease Control and Prevention (CDC). National Center for Health Statistics (NCHS). National Health and Nutrition Examination Survey. Hyattsville, MD: U.S. Department of Health and Human Services, Centers for Disease Control and Prevention, 2005-2006. http://www.cdc.gov/nchs/ about/major/nhanes/datalink.htm. Accessed March 23, 2009.

19. Blayney MJ, Pisoni RL, Bragg-Gresham JL, Bommer J, Piera L, Saito A, et al. High alkaline phosphatase levels in hemodialysis patients are associated with higher risk of hospitalization and death. Kidney Int 2008;74:655-63.

20. Luc G, Bard JM, Juhan-Vague I, Ferrieres J, Evans A, Amouyel $\mathrm{P}$, et al. C-Reactive protein, interleukin-6, and fibrinogen as predictors of coronary heart disease: the PRIME study. Arterioscler Thromb Vasc Biol 2003;23:1255-61. 
21. Kuller LH, Tracy RP, Shaten J, Meilahn EN. Relation of Creactive protein and coronary heart disease in the MRFIT nested case-control study. Multiple risk factor intervention trial. Am J Epidemiol 1996;144:537-47.

22. Targher G, Arcaro G. Non-alcoholic fatty liver disease and increased risk of cardiovascular disease. Atherosclerosis 2007; 191:235-40.

23. Nasri H, Baradaran A, Naderi AS. Close association between parathyroid hormone and left ventricular function and structure in end-stage renal failure patients under maintenance hemodialysis. Acta Med Austriaca 2004;31:67-72.

24. Salgueira M, Milan JA, Moreno Alba R, Amor J, Aresté N, Jiménez E, et al. Cardiac failure and diastolic dysfunction in hemodialysis patients: associated factors. Nefrologia 2005; 25:668-77.

25. Ali AT, Penny CB, Paiker JE, Psaras G, Ikram F, Crowther NJ. The effect of alkaline phosphatase inhibitors on intracellular lipid accumulation in preadipocytes isolated from human mammary tissue. Ann Clin Biochem 2006;43:207-13.

26. Domar U, Karpe F, Hamsten A, Stigbrand T, Olivecrona T. Human intestinal alkaline phosphatase-release to the blood is linked to lipid absorption, but removal from the blood is not linked to lipoprotein clearance. Eur J Clin Invest 1993;23: 753-60.

27. Narisawa S, Harmey D, Yadav MC, O’Neill WC, Hoylaerts MF, Millán JL. Novel inhibitors of alkaline phosphatase sup- press vascular smooth muscle cell calcification. J Bone Miner Res 2007;22:1700-10.

28. Daimon M, Oizumi T, Saitoh T, Kameda W, Hirata A, Yamaguchi $\mathrm{H}$, et al. Decreased serum levels of adiponectin are a risk factor for the progression to type 2 diabetes in the Japanese population: the Funagata study. Diabetes Care 2003;26:201520.

29. Chow WS, Cheung BM, Tso AW, Xu A, Wat NM, Fong CH, et al. Hypoadiponectinemia as a predictor for the development of hypertension: a 5-year prospective study. Hypertension 2007;49:1455-61.

30. Abedin M, Tintut Y, Demer LL. Vascular calcification: mechanisms and clinical ramifications. Arterioscler Thromb Vasc Biol 2004;24:1161-70.

31. Lomashvili KA, Garg P, Narisawa S, Millan JL, O’Neill WC. Upregulation of alkaline phosphatase and pyrophosphate hydrolysis: potential mechanism for uremic vascular calcification. Kidney Int 2008;73:1024-30.

32. Wang TJ, Pencina MJ, Booth SL, Jacques PF, Ingelsson E, Lanier K, et al. Vitamin D deficiency and risk of cardiovascular disease. Circulation 2008;117:503-11.

33. Mora S, Ridker PM. Justification for the use of statins in primary prevention: an intervention trial evaluating rosuvastatin (JUPITER) - can C-reactive protein be used to target statin therapy in primary prevention? Am J Cardiol 2006;97:33-41. 